\title{
Corrigendum: Diversity, Distribution and Phylogeny of Hesionidae (Annelida) Colonizing Whale Falls: New Species of Sirsoe and Connections Between Ocean Basins
}

\section{OPEN ACCESS}

Edited and reviewed by: Chong Chen, Japan Agency for Marine-Earth Science and Technology (JAMSTEC), Japan

${ }^{*}$ Correspondence: Mauricio Shimabukuro maushima@usp.br; mshima84@gmail.com

${ }^{\dagger}$ Present address:

Mauricio Shimabukuro and Joan Manel Alfaro-Lucas, Institut Français de Recherche pour l'Exploitation de la Mer (IFREMER), Centre de Bretagne, REM/EEP, Institut Carnot EDROME, Plouzané, France

Specialty section: This article was submitted to Marine Evolutionary Biology, Biogeography and Species Diversity, a section of the journal Frontiers in Marine Science

Received: 06 April 2021 Accepted: 03 May 2021 Published: 04 June 2021

Citation:

Shimabukuro M, Carrerette O,

Alfaro-Lucas JM, Rizzo AE, Halanych KM and Sumida PYG (2021) Corrigendum: Diversity, Distribution and Phylogeny of Hesionidae (Annelida) Colonizing Whale Falls: New Species of Sirsoe and Connections

Between Ocean Basins.

Front. Mar. Sci. 8:691503. doi: 10.3389/fmars.2021.691503

\section{Mauricio Shimabukuro ${ }^{1 *}$, Orlemir Carrerette ${ }^{1}$, Joan Manel Alfaro-Lucas ${ }^{1 \dagger}$, Alexandra Elaine Rizzo ${ }^{2}$, Kenneth M. Halanych ${ }^{3}$ and Paulo Yukio Gomes Sumida ${ }^{1}$}

\begin{abstract}
1 Departamento de Oceanografia Biológica, Instituto Oceanográfico, Universidade de São Paulo, São Paulo, Brazil, ${ }^{2}$ Laboratório de Zoologia de Invertebrados, Departamento de Zoologia, Instituto de Biologia, Universidade do Estado do Rio de Janeiro, Rio de Janeiro, Brazil, ${ }^{3}$ Molette Biology Laboratory for Environmental and Climate Change Studies, Department of Biological Sciences, Auburn University, Auburn, AL, United States
\end{abstract}

Keywords: deep sea, biodiversity, cryptic species, biogeography, connectivity

\section{A Corrigendum on}

Diversity, Distribution and Phylogeny of Hesionidae (Annelida) Colonizing Whale Falls: New Species of Sirsoe and Connections Between Ocean Basins

by Shimabukuro, M., Carrerette, O., Alfaro-Lucas, J. M., Rizzo, A. E., Halanych, K. M., and Sumida, P. Y. G. (2019) Front. Mar. Sci. 6:478. doi: 10.3389/fmars.2019.00478

In the original article, the Zoobank registration is missing for all the new species proposed. Here we included the Zoobank registration followed by the nomenclatural acts (species description) in accordance with Article 8.5.3 (ICZN, 1999) in order for the names to be valid. All figures and remarks can be found in the original article, but the new species are nomenclaturally available and valid from this corrigendum. Several corrections have been made to include Zoobank registration and the updated sections are as follow:

Abstract: Inclusion of Zoobank resgistration publication LSID "Zoobank registration publication LSID - urn:lsid:zoobank.org:pub:7E891B1D-DCE4-45C8-83F4-8586D286B327.” The corrected text is: "Our data adds to the growing literature showing species are shared between deep ocean basins and among cognate deep-sea environments. Zoobank registration publication LSID urn:Isid:zoobank.org:pub:7E891B1D-DCE4-45C8-83F4-8586D286B327"

Results, Sirsoe, Paragraph 1:

The corrected text is: "Sirsoe Pleijel, 1998 emended

urn:lsid:zoobank.org:act:AED41380-D297-4F21-A119-3B55DEDC7A2B

Type species: Sirsoe grasslei (Blake, 1985)

Vrijenhoekia Pleijel et al. (2008), new synonymy. Type species Vrijenhoekia balaenophila (new combination Sirsoe balaenophila)."

Results, Sirsoe, Paragraph 3:

"Diagnosis: Psamathinae with reduced small-depression-like nuchal organs not projected on posterior margin of prostomium (Figure 4C), frontal tubercle present (Figures 5E, 6C, 7B), with (Figures $4 \mathrm{~A}, \mathrm{C}$ ) or without (Figures 5F, 6C, 7B, 8A, 9C, 10B, 11D, 12A) dorsally median antenna, eyes absent, with or without glandular lip pads." 


\section{Results, Sirsoe balaenophila, Paragraph 1-3:}

The corrected text is: "Sirsoe balaenophila (Pleijel et al., 2008) comb. nov.

urn:lsid:zoobank.org:act:42715732-148D-47EE-B7FC-

AAAC5613AA90 (Figure 6A)

Material examined: One specimen from SW Atlantic, $21.450^{\circ} \mathrm{S}, \quad 39.897^{\circ} \mathrm{W}, 1444 \mathrm{~m}$ (ColBio DS00141; GenBank: MH935085 and MH935162), incomplete, 19 chaetigers, $14 \mathrm{~mm}$ length, $2.5 \mathrm{~mm}$ width; One specimen from SW Atlantic, $25.338^{\circ} \mathrm{S}, 39.642^{\circ} \mathrm{W}$, $3227 \mathrm{~m}$ (ColBio DS00142; GenBank: MH935092 and MH935165), incomplete, 9 chaetigers, $7 \mathrm{~mm}$ length, $1.8 \mathrm{~mm}$ width; Six specimens from SW Atlantic, $25.338^{\circ} \mathrm{S}, 39.642^{\circ} \mathrm{W}, 3227 \mathrm{~m}$ (ColBio DS00143), incomplete; One specimen from SW Atlantic, $28.029^{\circ} \mathrm{S}, 43.530^{\circ} \mathrm{W}, 3328 \mathrm{~m}$ (ColBio DS00144), incomplete.

Description: Body stout and tapering to posterior region (Figure 6A). Live specimens reddish (Figure 6A); preserved specimens whitish to pale yellowish. Prostomium wider than long, nearly rectangular; prostomium forming a swollen ridge basally to the prostomium, extending laterally to the first parapodia. Eyes absent. One pair of small-depression-like nuchal organs posteriorly on the prostomium. Frontal tubercle distinct, robust and directed toward anterior end. Palps biarticulated; palpophore cylindrical; palpostyle conical, short, up to half of the length of palpophore. Terminal proboscis with ten filiform papillae and dense ciliation among each papilla. Three pairs of distinct well-developed glandular lip pads. Lateral antennae slender and slightly longer than palps; median antenna absent. Dorsal cirri of first five segments enlarged with distinct cirrophores. Ventral cirri slender, shorter than dorsal ones; ventral cirri enlarged with distinct cirrophores on first three segments; following ventral cirri with inconspicuous cirrophores as basal swollen on ventral margin of neuropodia. Noto- and neuropodial lobes and chaetae absent on first two segments; neuropodial lobe on third segment papilliform, usually without chaetae; following segments with distinct neuropodial lobes. Anterior neuropodia with 5-8 supra-acicular and subacicular neurochaetae; mid- to posterior neuropodia with 2530 supra-acicular and 20-25 sub-acicular neurochaetae, last 45 neuropodia as anterior ones; supra- and sub-acicular chaetae with same shape; chambered shafts and long blades; blades ca. 15 times longer than wide. Cutting edge of blades finely serrated, distally unidentate, distal teeth sharply curved with sub-distal enlarged prolongation, resembling an empty balloon. Pygidium small, with a pair of long pygidial cirri as long as last dorsal cirri."

Results, Sirsoe ypupiara sp. nov, Paragraph 1-3:

The corrected text is: "Sirsoe ypupiara sp. nov.

urn:lsid:zoobank.org:act:4DAB33F7-CC20-4665-88B1-

11B5AA9ABC43 (Figures 6B-D)

Material examined: Holotype from SW Atlantic, $25.338^{\circ} \mathrm{S}$, $39.642^{\circ} \mathrm{W}, 3227 \mathrm{~m}$ (MZUSP 3357; GenBank: MH935119 and MH935179), incomplete 10 chaetigers, $10 \mathrm{~mm}$ length, $3.2 \mathrm{~mm}$ width; Paratype from SW Atlantic, $25.338^{\circ} \mathrm{S}, 39.642^{\circ} \mathrm{W}$, $3227 \mathrm{~m}$ (MZUSP 3358; GenBank: MH935111 and MH935187), incomplete 12 chaetigers, $19 \mathrm{~mm}$ length, $3.2 \mathrm{~mm}$ width; Paratype from SW Atlantic, $25.338^{\circ} \mathrm{S}, 39.642^{\circ} \mathrm{W}, 3227 \mathrm{~m}$ (ColBio DS00150; GenBank: MH935117 and MH935190), incomplete
11 chaetigers, $12 \mathrm{~mm}$ length, $2 \mathrm{~mm}$ width; One specimen on SEM stub from SW Atlantic, $25.338^{\circ} \mathrm{S}, 39.642^{\circ} \mathrm{W}, 3227 \mathrm{~m}$ (MZUSP 3578).

Description: Morphologically identical to S. balaenophila. Frontal tubercle longer than wide with rounded anterior end (Figures 6B,C). The base of frontal tubercle wider than anterior end. Three pairs of glandular lip pads being the ventral pair wider than long while the dorsal and lateral ones as wide as long (Figures 6B,C). Papilliform neuropodial lobe on third segment present, without chaetae (Figure 6D). Mid-body neuropodia with approximately 35 supra-acicular and sub-acicular neurochaetae. Neurochaetae with chambered shafts and blades ca. 13 times longer than wide. Cutting edge of blades finely serrated, distally unidentate, distal teeth curved with sub-distal enlarged prolongation, resembling an empty balloon (Figure 6D).

Results, Sirsoe pirapuan sp. nov., Paragraph 1-3:

The corrected text is: "Sirsoe pirapuan sp. nov.

urn:lsid:zoobank.org:act:A6AB0868-4211-40D8-B776-

0A68F22EB4F9 (Figures 6E-H)

Material examined: Holotype from SW Atlantic, $21.450^{\circ} \mathrm{S}$, $39.897^{\circ} \mathrm{W}, 3211 \mathrm{~m}$ (MZUSP 3355; GenBank: MH935102 and MH935189), incomplete, 12 chaetigers, $8 \mathrm{~mm}$ length, $1.8 \mathrm{~mm}$ width; Paratype from SW Atlantic, $21.450^{\circ} \mathrm{S}, 39.897^{\circ} \mathrm{W}$, $3211 \mathrm{~m}$ (MZUSP 3356; GenBank: MH935096 and MH935178), incomplete, 7 chaetigers, $8 \mathrm{~mm}$ length, $2 \mathrm{~mm}$ width; Three specimens from SW Atlantic, $21.450^{\circ} \mathrm{S}, 39.897^{\circ} \mathrm{W}, 3211 \mathrm{~m}$ (ColBio DS00147); Two specimens from SW Atlantic, $21.450^{\circ} \mathrm{S}$, $39.897^{\circ} \mathrm{W}, 1444 \mathrm{~m}$ (MZUSP 3573); One specimen on SEM stub from SW Atlantic, $21.450^{\circ} \mathrm{S}, 39.897^{\circ} \mathrm{W}, 1444 \mathrm{~m}$ (MZUSP 3577 ).

Description: Morphologically with diagnostic features of $S$. balaenophila. Three pairs of glandular lip pads being the ventral pair wider than long while the dorsal and lateral ones as wide as long (Figure 6E). Papilliform neuropodial lobe on third segment present, without chaetae (Figure 6F). Mid-body neuropodia with approximately 30 supra-acicular and sub-acicular neurochaetae (Figure 6H). Neurochaetae with chambered shafts and blades ca. 17 times longer than wide. Cutting edge of blades finely serrated, distally unidentate, distal teeth curved with sub-distal enlarged prolongation, resembling an empty balloon (Figure 6G)."

Results, Sirsoe maximiano sp. nov., Paragraph 1-3:

The corrected text is: "Sirsoe maximiano sp. nov.

urn:Isid:zoobank.org:act:73406A47-82FB-4183-A274402F4ED6622C (Figures 7A-E)

Material examined: Holotype from SW Atlantic, $25.894^{\circ} \mathrm{S}$, $45.035^{\circ} \mathrm{W}, 1439 \mathrm{~m}$ (MZUSP 3371; GenBank: MH935151 and MH935157), incomplete 17 chaetigers, $6 \mathrm{~mm}$ length, $1 \mathrm{~mm}$ width; Paratypes: two specimens from SW Atlantic, $25.894^{\circ} \mathrm{S}, 45.035^{\circ} \mathrm{W}$, $1439 \mathrm{~m}$ (ColBio DS00152); Paratypes: three specimens from SW Atlantic, $28.029^{\circ} \mathrm{S}, 43.530^{\circ} \mathrm{W}, 3328 \mathrm{~m}$ (MZUSP 3372); Two specimens on SEM stub from SW Atlantic, $25.894^{\circ} \mathrm{S}, 45.035^{\circ} \mathrm{W}$, $1439 \mathrm{~m}$ (MZUSP 3579 and MZUSP 3580).

Description: Body stout, highly tapering from mid- to posterior body (Figure 7A); preserved specimens whitish to pale yellowish. Prostomium slightly wider than long. Eyes absent. Paired small-depression-like nuchal organs posteriorly on prostomium (Figure 7C). Frontal tubercle restricted to small pad, with the margin slightly crenulated (Figures 7C,E). 
Palps biarticulated; palpophores cylindrical, short and robust; palpostyles conical, twice or more the length of palpophores. Lateral antennae cirriform, longer than palps; median antenna absent. Proboscis with ten filiform terminal papillae covered by dense ciliation among each papilla (Figure 7B). Glandular lip pads absent. First three segments totally fused, with enlarged dorsal cirri longer than the following ones; dorsal cirrophores cylindrical throughout the body, shorter in anterior and posterior regions. Ventral cirri slender, progressively more distally inserted on neuropodia in posterior region; cirri of segments 1-3 enlarged, more robust than in following segments, inserted in distinct cirrophores; following ventral cirri not exceed the length of neuropodia. Parapodia sub-birramous with notopodia reduced to the dorsal cirrophores and neuropodia well developed, with 2-3 noto- and neuroaciculae. Neuropodia and neurochaetae starting on segment 3 , with long and tapering acicular lobule. Anterior and posterior neuropodia with 10-15 supra-acicular and 15-20 sub-acicular neurochaetae, mid-body with 25-28 supra-acicular and 15-20 sub-acicular neurochaetae; all with chambered shafts and long blades; supra-acicular chaetae from anterior and posterior region with blades ca. 8 times shorter than those blades from mid-body; blades of supra-acicular chaetae ca. 4 times the longer than subacicular ones, in anterior and posterior regions, from median region ca. 20 times longer. Neurochaetae shafts from midbody longer than those from anterior and posterior regions; cutting edges of all blades are unidentate, finely serrate with sub-distal prolongation like an arista (Figure 7D). Pygidium not observed."

\section{Results, Sirsoe alphacrucis sp. nov., Paragraph 1-3:}

The corrected text is: "Sirsoe alphacrucis sp. nov.

urn:1sid:zoobank.org:act:7992F3BC-08F6-4B9F-B608-

C08E8807E268 (Figures 8A-F)

Material examined: Holotype from SW Atlantic, $25.894^{\circ} \mathrm{S}$, $45.035^{\circ} \mathrm{W}, 1439 \mathrm{~m}$ (MZUSP 3363), complete 23 chaetigers, $4 \mathrm{~mm}$ length, $0.5 \mathrm{~mm}$ width; Paratype from SW Atlantic, $25.894^{\circ} \mathrm{S}$, $45.035^{\circ} \mathrm{W}, 1439 \mathrm{~m}$ (MZUSP 3364; GenBank: MH935140 and MH935191), complete 19 chaetigers, $3.5 \mathrm{~mm}$ length, $0.3 \mathrm{~mm}$ width; Paratype from SW Atlantic, $25.894^{\circ} \mathrm{S}, 45.035^{\circ} \mathrm{W}, 1439 \mathrm{~m}$ (ColBio DS00156); Paratypes from SW Atlantic, $21.450^{\circ} \mathrm{S}$, $39.897^{\circ} \mathrm{W}, 1444 \mathrm{~m}$ (eight specimens, MZUSP 3570), (two specimens, MZUSP 3571), (three specimens, MZUSP 3572); 19 specimens from SW Atlantic, $25.894^{\circ} \mathrm{S}, 45.035^{\circ} \mathrm{W}, 1439 \mathrm{~m}$ (MZUSP 3365); One specimen in SEM stub from SW Atlantic $25.894^{\circ} \mathrm{S}, 45.035^{\circ} \mathrm{W}, 1439 \mathrm{~m}$ (MZUSP 3581).

Description: Thin cylindrical body, usually not flattened. Preserved specimens with brownish pigmentation on anterior segments, concentrated laterally between prostomium and first segments, forming a mask or covering the entire prostomium. Prostomium as wide as long, nearly squared (Figures $8 \mathrm{~A}, \mathrm{~B}$ ). Eyes absent, even though sometimes the pigmentation on the prostomium resembles two big eyes. Nuchal organs as small-depression, posteriorly on prostomium. Frontal tubercle inconspicuous as mild swelling (Figure 8B). Palps biarticulated; palpophores robust and cylindrical, as wide as long, and slightly shorter than palpostyles; palpostyles conical (Figures 8A,B). Lateral antennae slender, cirriform to conical, thinner than palps; median antenna absent (Figures 8A,B). Glandular lip pads present; one dorsal and one ventro-lateral pairs, not easily distinguishable. Everted proboscis with ten cirriform terminal papillae, densely ciliated among each papilla (Figures 8A,B). First two segments totally fused, the third partially fused with the second. Dorsal cirri of the first two segments enlarged, longer and more robust than following ones. Ventral cirri enlarged on first two segments and inserted in small cirrophores, being the first ventral cirri longer than the second; following ventral cirri attached to the base of neuropodia, as long as or slightly longer than the acicular lobule. Parapodia subbirramous with notopodia reduced to dorsal cirrophores bearing 1-2 notoaciculae. First neuropodia on segment 3 (Figure $8 \mathrm{~A}$ ), 2-3 times smaller than second neuropodial, following segments with neuropodia about same size; neuropodia short with slender acicular lobule and 2-3 neuroaciculae. Anterior and posterior neuropodia with $\sim 7-9$ supra-acicular and 5-7 sub-acicular neurochaetae (Figure 8C); all compound neurochaetae with shafts all chambered. Blades up to 10 times longer than wide, with about same length along the body (Figure 8D). Cutting edge of blades finely serrated, distally unidentate, curved, with a sub-distal spoon-like prolongation, distally inflated, projecting toward to the distal tooth (Figure 8E); under light microscopy the sub-distal prolongation seems a hood. A pair of pygidial cirri and dorsal pygidial papilla present (Figure $8 \mathrm{~F}$ ).”

Results, Sirsoe yokosuka sp. nov., Paragraph 1-3:

The corrected text is: "Sirsoe yokosuka sp. nov.

urn:lsid:zoobank.org:act:F58CBAF8-F227-43A7-AA62-

87E590598A39 (Figures 9A-F)

Material examined: Holotype from SW Atlantic, $25.338^{\circ} \mathrm{S}$, $39.642^{\circ} \mathrm{W}, 3227 \mathrm{~m}$ (MZUSP 3366), complete 19 chaetigers, $3.5 \mathrm{~mm}$ length, $0.4 \mathrm{~mm}$ width; Paratype from SW Atlantic, $22.841^{\circ} \mathrm{S}, \quad 38.416^{\circ} \mathrm{W}, \quad 3211 \mathrm{~m}$ (MZUSP 3367; GenBank: MH935141 and MH935196), incomplete 14 chaetigers, $4 \mathrm{~mm}$ length, $0.4 \mathrm{~mm}$ width; Paratypes: five specimens, SW Atlantic, $25.338^{\circ} \mathrm{S}, 39.642^{\circ} \mathrm{W}, 3227 \mathrm{~m}$ (ColBio DS00160); Three specimens from SW Atlantic, $28.519^{\circ} \mathrm{S}, 41.657^{\circ} \mathrm{W}, 4204 \mathrm{~m}$ (ColBio DS00161); Four specimens from SW Atlantic, $28.029^{\circ} \mathrm{S}$, $43.530^{\circ} \mathrm{W}, 3328 \mathrm{~m}$ (MZUSP 3567); 13 specimens from SW Atlantic, $25.338^{\circ} \mathrm{S}, 39.642^{\circ} \mathrm{W}, 3227 \mathrm{~m}$ (MZUSP 3568); Nine specimens from SW Atlantic, $25.338^{\circ} \mathrm{S}, 39.642^{\circ} \mathrm{W}, 3227 \mathrm{~m}$ (MZUSP 3569). Three specimens on SEM stub from SW Atlantic, $28.519^{\circ} \mathrm{S}, 41.657^{\circ} \mathrm{W}, 4204 \mathrm{~m}$ (MZUSP 3575); One specimen in SEM stub from SW Atlantic, $25.338^{\circ} \mathrm{S}, 39.642^{\circ} \mathrm{W}$, 3227 m (MZUSP 3576).

Description: Thin cylindrical body, not flattened. Prostomium rounded slightly wider than long (Figure 9A), covered by a spread dark pigmentation. Palps biarticulated; palpophores robust and cylindrical, as wide as long, and slightly shorter than palpostyles; palpostyles conical (Figure 9A). Lateral antennae slender, conical, thinner than palps; median antenna absent (Figure 9A). Everted proboscis with ten cirriform terminal papillae, densely ciliated among each papilla; cilia long, exceeding the length of terminal papillae (Figure 9B). Other morphological features as $S$. alphacrucis sp. nov."

Results, Sirsoe alucia sp. nov., Paragraph 1-3:

The corrected text is: "Sirsoe alucia sp. nov. 
urn:lsid:zoobank.org:act:91E91094-DF25-4F96-9AD8-

F48212DA92BB (Figures 10A-E)

Material examined: Holotype from SW Atlantic, $26.600^{\circ} \mathrm{S}$, $46.150^{\circ} \mathrm{W}, 550 \mathrm{~m}$ (MZUSP 3359; GenBank: MH935128 and MH935204), incomplete 14 chaetigers, $4 \mathrm{~mm}$ length, $1.3 \mathrm{~mm}$ width; Paratype from SW Atlantic, $26.600^{\circ} \mathrm{S}, 46.150^{\circ} \mathrm{W}$, $550 \mathrm{~m}$ (MZUSP 3360; GenBank: MH935127 and MH935158), incomplete 12 chaetigers, $6 \mathrm{~mm}$ length, $2 \mathrm{~mm}$ width; Paratypes: Seven specimens from SW Atlantic, $26.600^{\circ} \mathrm{S}, 46.150^{\circ} \mathrm{W}, 550 \mathrm{~m}$ (ColBio DS00164); One specimen in SEM stub from SW Atlantic, $26.600^{\circ} \mathrm{S}, 46.150^{\circ} \mathrm{W}, 550 \mathrm{~m}$ (MZUSP 3582).

Description: Body stout, tapering from median to posterior region (Figure 10A); preserved specimens pale brownish to reddish on body and parapodia with darker coloration. Prostomium wider than long (Figure 10B), with region between prostomium and first segment densely pigmented, pigmentation brownish-red to purple (Figure 10A); prostomium basally forming a swollen ridge, extending laterally to the first parapodia (Figure 10C). Eyes absent. One pair of smalldepression-like nuchal organ posteriorly on the prostomium (Figure 10C). Frontal tubercle inconspicuous as small pad with crenulated margin (Figures 10B,C). Palps biarticulated; palpophores cylindrical; palpostyles conical, usually half of the length of palpophores (Figures 10B,C). Lateral antennae filiform and slightly longer than palps; median antenna absent (Figure 10C). Glandular lip pads absent. Proboscis with ten foliaceous terminal papillae (Figure 10D), covered by dense ciliation among each papilla; ciliation short, not exceeding the length of papillae (Figures 10B-D). First three segments fused. Dorsal cirri of first five segments longer than the following ones, usually exceeding half of the length of the body (Figure 10A). Enlarged ventral cirri on segments 1-3, with distinct cirrophore (Figure 10D); following segments with ventral cirri up to the length of acicular lobule; cirrophores of these ventral cirri as mild swellings, not easily distinguishable. Parapodia sub-biramous with notopodia reduced to the dorsal cirrophores and neuropodia well developed, with 3-4 notoand neuroaciculae. Neuropodia and neurochaetae starting on segment 3, with long and tapered acicular lobule. Anterior and posterior neuropodia with 7-15 supra-acicular and 1020 sub-acicular neurochaetae, mid-body neuropodia with 2035 supra- and sub-acicular ones; neurochaetae dark, from grayish amber to black color; supra-acicular neurochaetae with long blades (up to 50 times longer than wide) (Figure $10 \mathrm{E}$ ) and sub-acicular with short blades (usually less than 25 times longer than wide). The difference in the length of the supra-acicular and sub-acicular blades are more distinct in median region of the body. Cutting edges of all blades are finely serrated, distally unidentate, curved, with a thin subdistal spine-like prolongation (Figure 10E). Pygidial cirri paired and terminal."

Results, Sirsoe nadir sp. nov., Paragraph 1-3:

The corrected text is: "Sirsoe nadir sp. nov.

urn:lsid:zoobank.org:act:F264A645-D68C-442B-9D4D-

B0DBFA85735D (Figures 11A-D)

Material examined: Holotype from SW Atlantic, $26.600^{\circ} \mathrm{S}$, $46.150^{\circ} \mathrm{W}, 550 \mathrm{~m}$ (MZUSP 3361), complete 25 chaetigers, $4.5 \mathrm{~mm}$ length, $1 \mathrm{~mm}$ width; Paratype from SW Atlantic, $26.600^{\circ} \mathrm{S}$, $46.150^{\circ} \mathrm{W}, 550 \mathrm{~m}$ (MZUSP 3362; GenBank: MH935129 and MH935200), incomplete 19 chaetigers, $5 \mathrm{~mm}$ length, $1.3 \mathrm{~mm}$ width; Three specimen from SW Atlantic, $26.600^{\circ} \mathrm{S}, 46.150^{\circ} \mathrm{W}$, $550 \mathrm{~m}$ (ColBio DS00167); One specimen in SEM stub from SW Atlantic, $26.600^{\circ} \mathrm{S}, 46.150^{\circ} \mathrm{W}, 550 \mathrm{~m}$ (MZUSP 3583).

Description: Body short and slender with no evidence of posterior tapering; preserved specimens pale brownish to yellowish. Prostomium at least twice wider than long (Figures $11 \mathrm{~A}, \mathrm{~B})$. Eyes absent. One pair of small depression-like nuchal organ posteriorly on the prostomium. Frontal tubercle present as distinct rounded prolongation. Palps biarticulated (Figures 11A,B); palpophores cylindrical, about same length of palpostyle; palpostyles conical. Lateral antennae cirriform about same length of palps; median antenna absent (Figures 11A,B). Two pairs of indistinct glandular lip pads; one dorsal and one lateral (Figure 11B). Proboscis with ten cirriform terminal papillae, covered by dense ciliation among each papilla (Figures $11 B, C$ ). First two segments fused. Dorsal cirri of first two segments longer than the following ones. Ventral cirri of first three segments inserted in distinct cirrophores and more robust than the following ones; from the fourth segment ventral cirri inserted on neuropodial lobe, not exceeding the length of neuropodia in anterior and mid-body; ventral cirri of posterior region exceed the length of neuropodia. Parapodia subbirramous with notopodia reduced to dorsal cirrophores with 2-3 notoaciculae and neuropodia well developed starting on segment 3 (Figure 11A), bearing 3-4 neuroaciculae. Neuropodia with acicular lobule long and tapering, distally pointed, with a mid-neuroacicula. Neurochaetae with shafts chambered; 7-10 supra-acicular and 5-10 sub-acicular in anterior and posterior region; 12-15 supra-acicular and 15-20 sub-acicular in midbody. Shafts of supra-acicular chaetae usually one third longer than shafts of sub-acicular ones; supra-acicular chaetae with blades 20-25 times longer than wide; sub-acicular ones 1015 times longer than wide. Cutting edges of all blades finely serrate, distally unidentate, curved, with sub-distal spine-like prolongation; sub-distal ones projected like an arista to distal teeth (Figure 11D). Pygidium and pygidial cirri not observed."

Results, Sirsoe alphadelphini sp. nov., Paragraph 1-3:

The corrected text is: "Sirsoe alphadelphini sp. nov.

urn:lsid:zoobank.org:act:69616969-9477-40FA-949F-

773EECA1E4E1 (Figures 12A,B)

Material examined: Holotype from SW Atlantic, $25.338^{\circ} \mathrm{S}$, $39.642^{\circ} \mathrm{W}, 3227 \mathrm{~m}$ (MZUSP 3373), incomplete four chaetiger, $3 \mathrm{~mm}$ length, $1.8 \mathrm{~mm}$ width; Paratype from SW Atlantic, 25.338 $\mathrm{S}$, $39.642^{\circ} \mathrm{W}, 3227 \mathrm{~m}$ (ColBio DS00168; GenBank: MH935132 and MH935203); Paratype from SW Atlantic, 21.450 $\mathrm{S}, 39.897^{\circ} \mathrm{W}, 1444 \mathrm{~m}$ (MZUSP 3574).

Description: Body slender and short, slightly flattened in anterior region, posterior region not observed. Preserved specimen whitish. Prostomium slightly wider than long (Figure 12A). Eyes absent. Nuchal organs as small-depression, positioned posteriorly on the prostomium. Frontal tubercle as a small pad, inconspicuous. Palps biarticulated; palpophores cylindrical, longer than palpostyles; palpostyles conical. Lateral antennae cirriform as long as palps; median antenna absent. Glandular 
lip pads absent. Proboscis with 11 cirriform terminal papillae, covered ciliation among each papilla (Figure 12B). First two segments fused. Dorsal cirri longer on first two segments. Ventral cirri enlarged on first three segments, inserted in cirrophores in segments 1-2; third ventral cirri not inserted on neuropodium but cirrophore not evident; following ventral cirri inserted on neuropodia. Parapodia sub-birramous with notopodia reduced to dorsal cirrophores bearing 1-2 notoaciculae and neuropodia well developed with 2-3 neuroaciculae. Neurochaetae with chambered shafts and long blades along the body, shafts from mid-body longer than those from anterior region; supra-acicular chaetae from anterior region with blades ca. 8 times shorter than those blades from middle body region; blades of supra-acicular chaetae from middle body region ca. 20 times longer than subacicular ones. Cutting edge of all blades finely serrated, distally unidentate, curved, with a sub-distal spine-like prolongation. Pygidium not observed."

Results, Sirsoe ungava sp. nov., Paragraph 1-3:

The corrected text is: "Sirsoe ungava sp. nov.

urn:lsid:zoobank.org:act:0D1137E6-B44A-476E-BFAE-

4A52EF0A9B99 (Figures 12C-E)

Material examined: Holotype from SW Atlantic, $21.450^{\circ} \mathrm{S}$, $39.897^{\circ} \mathrm{W}, 1444 \mathrm{~m}$ (MZUSP 3368), complete 30 chaetigers, $9.3 \mathrm{~mm}$ length, $1.1 \mathrm{~mm}$ width, without chaetigers; Paratype from SW Atlantic, $28.029^{\circ} \mathrm{S}, 43.530^{\circ} \mathrm{W}, 3328 \mathrm{~m}$ (MZUSP 3369; GenBank: MH935145 and MH935160), incomplete 12 chaetigers, $2.7 \mathrm{~mm}$ length, $1.0 \mathrm{~mm}$ width, without chaetigers; Paratype from SW Atlantic, $21.450^{\circ} \mathrm{S}, 39.897^{\circ} \mathrm{W}, 1444 \mathrm{~m}$ (ColBio DS00170), incomplete 5 segments, $2.1 \mathrm{~mm}$ length and $1.0 \mathrm{~mm}$ width, without chaetigers; Paratype from SW Atlantic, $21.450^{\circ} \mathrm{S}$, 39.897 ${ }^{\circ} \mathrm{W}, 1444 \mathrm{~m}$ (ColBio DS00171).

Description: Body stout and cylindrical, tapering from mid-body to posterior region (Figures 12C,D); preserved specimens yellowish. Prostomium wider than long (Figure 12D). Eyes absent. One pair of small-depression-like nuchal organ, posteriorly on the prostomium. Frontal tubercle distinct as rounded triangular prolongation (Figures 12C,D). Palps biarticulated; palpophores cylindrical slightly shorter or as long as palpostyles; palpostyles conical. Lateral antennae filiform slightly longer than palps (Figure 11C); median antenna absent. Glandular lip pads absent. Proboscis with ten minute terminal papillae, not densely ciliated among each papilla (Figures 12C,E). First two segments fused. Dorsal cirri of first three segments more robust than the following ones; third dorsal cirri twice longer than the previous ones. Ventral cirri inserted in distinct cirrophores on first three segments. Following ventral cirri inserted from mid to distal end of neuropodial lobe and slightly longer than acicular lobule. Parapodia sub-biramous with notopodia reduced to dorsal cirrophores and neuropodia well developed with 1-2 noto- and neuroaciculae. Neuropodia and neurochaetae starting on third segment (Figure 12C); neuropodial lobe short and stout with pointed acicular lobule. Each neuropodia with 10-15 supra-acicular and 5-10 subacicular neurochaetae along the body. Pygidium simple, pygidial cirri not observed."

Results, Sirsoe besnard sp. nov., Paragraph 1-3:

The corrected text is: "Sirsoe besnard sp. nov.

urn:lsid:zoobank.org:act:D1272F00-3CF6-4818-BE71-

B5617FE75FF4 (Figures 13A-C)

Material examined: Holotype in SEM stub from SW Atlantic, $25.338^{\circ} \mathrm{S}, 39.642^{\circ} \mathrm{W}, 3227 \mathrm{~m}$ (MZUSP 3370; GenBank: MH935147 and MH935199).

Description: Body stout, short and cylindrical, not tapered; preserved specimen pale yellowish. Prostomium wider than long (Figure 13A). Eyes absent. Nuchal organs as small-depression, positioned posteriorly on the prostomium. Frontal tubercle present, but inconspicuous (Figure 13A). Palps biarticulated; palpophores cylindrical longer than palpostyles; palpostyles conical. Lateral antennae cirriform slightly longer than palps; median antenna absent. Glandular lip pads absent. Proboscis with ten filiform terminal papillae, covered by ciliation among each papilla (Figure 13B). First two segments fused. Dorsal cirri of segments 1-2 longer than the following ones. Ventral cirri from segments 1-3 inserted in distinct cirrophores longer than the followings ones. Parapodia sub-biramous with notopodia reduced to dorsal cirrophores and neuropodia well developed starting on segment 3 bearing 1-2 noto- and neuroaciculae. Neuropodia with slender acicular lobule and 15-20 supra-acicula and sub-acicular neurochaetae; blades of neurochaetae usually 20-25 times longer than wide. Cutting edge of all blades basally finely serrated and distally smooth and unidentate, tooth curved, with a sub-distal spine-like prolongation (Figure 13C). Pygidium not observed."

The authors apologize for this error and state that this does not change the scientific conclusions of the article in any way. The original article has been updated.

Copyright (c) 2021 Shimabukuro, Carrerette, Alfaro-Lucas, Rizzo, Halanych and Sumida. This is an open-access article distributed under the terms of the Creative Commons Attribution License (CC BY). The use, distribution or reproduction in other forums is permitted, provided the original author(s) and the copyright owner(s) are credited and that the original publication in this journal is cited, in accordance with accepted academic practice. No use, distribution or reproduction is permitted which does not comply with these terms. 